\title{
A Descriptive, Cross-Sectional Study of Ugandan Students in Health Care Education regarding Postgraduate Migration and Future Practice
}

\author{
Arabat Kasangaki, ${ }^{1,2}$ Andrew Macnab,, 3 and Faith Gagnon ${ }^{4}$ \\ ${ }^{1}$ College of Health Sciences, Makerere University, Kampala 7072, Uganda \\ ${ }^{2}$ Stellenbosch Institute for Advanced Study (STIAS), Wallenberg Research Centre at Stellenbosch University, Marais Street, \\ Stellenbosch 7600, South Africa \\ ${ }^{3}$ Department of Pediatrics, University of British Columbia, Vancouver, BC, Canada V6N 3N1 \\ ${ }^{4}$ Gagnon Research Associates, Surrey, BC, Canada V4A 1 T7
}

Correspondence should be addressed to Arabat Kasangaki, arabat55@gmail.com

Received 27 December 2011; Accepted 1 February 2012

Academic Editor: T. A. Betts

Copyright (C) 2012 Arabat Kasangaki et al. This is an open access article distributed under the Creative Commons Attribution License, which permits unrestricted use, distribution, and reproduction in any medium, provided the original work is properly cited.

\begin{abstract}
A growing challenge of globalization is the migration of many healthcare trainees to richer nations when they complete their education. This loss of intellectual capital compromises the ability of low-income countries to provide adequate health care. Despite recognition of this loss most African nations keep no track of those they train. Effective investment in health care demands retention of this resource; the ability to direct healthcare providers where needed; understanding of local factors driving migration, choices regarding postgraduate training abroad, and future practice preference. Self-administered questionnaires were distributed to a random sample of 200 Uganda College of Health Sciences students for anonymous completion; 141/200 (70.5\%) were completed; $84 \%$ of respondents intended to pursue postgraduate studies abroad; $63 \%$ to migrate within five years of graduation; $57 \%$ to work in urban areas. While partly due to global trends and awareness of international opportunities, this negative trend of migration and shunning rural practice is also influenced by sociopolitical and educational elements within Uganda. One option (adopted elsewhere) is mandatory practice in government community health centers for a period following graduation. But the ethics, consequences, and implications of current international migratory trends need to be addressed locally and by the global medical education community.
\end{abstract}

\section{Background}

"All people everywhere shall have access to a skilled, motivated and facilitated health care worker within a robust health system" [1]. However, the global trend of migration by health workers from resourced-constrained countries to richer nations depletes the intellectual capital of these countries and compromises their ability to provide adequate healthcare [2]. In 2004 WHO reported that two thirds of healthcare workers interviewed in Africa had intentions to emigrate [3]. Developed countries are recognized to actively recruit health workers to fill positions in their countries [4], and the demand for international medical graduates is likely to grow [5]. Uganda like many other developing countries is facing a crisis over human resources for health (HRH), with the ongoing shortage of personnel likely contributing to both the poor maternal (MMR) and infant (IMR) mortality rates [6] (MMR 435 per 100,000) [7] (IMR 83 per 1000) [8]. While there are now four medical schools in Uganda (three public one private), and several other tertiary institutions providing training for health professions complementary to medicine, shortages driven in large part by migration of graduates continue to undermine the provision of equitable healthcare. Despite the large numbers of professionals migrating, and this problem being acknowledged by the World Health Organization, most African nations do not keep track of the healthcare professionals they train and then lose [9], and their level of national health funding negatively affects 
both retention and recruitment strategies both locally and internationally.

While the WHO Millennium Declaration (2000) [10] sets out governments' responsibilities and defines specific targets, universal access to appropriate health care remains a dream for nations like Uganda. Although there are estimated to be 950 health centers able to provide varying levels of care the majority remain without adequate staff both in numbers and skill mix. In rural health centers it is common for either no one to take up a posting, or for an individual who does to move on to a better paying job within or outside the country. Evidence from Uganda [11] and also Australia [12] indicates that the majority of healthcare workers have no intention of working in a rural setting.

There is a growing global concern about the large variation in availability of human resources for health (HRH) between the world's nations and the negative impact of their scarcity on health equity, health disparities, and the fight against HIV/AIDS and emerging diseases [2, 5, 13, 14]. Healthcare professionals are especially needed in Africa which has $24 \%$ of the global burden of disease, but only $3 \%$ of all healthcare professionals [15]. In sub-Saharan Africa, the rate of loss of healthcare workers is often greater than the replacement and production [16], and Uganda with a 14.2 emigration factor is one of the 20 nations with the highest rate of emigration [5]. Of the physicians born in Uganda $43 \%$ ( $n=1837)$ live and work outside the country [4].

In order to address provision of adequate numbers of healthcare professionals it is necessary to know more about the factors underlying decisions to migrate and consider how changes in education delivery methods and public policy might contribute. The College of Health Sciences, Makerere University (MakCHS), recently introduced an innovation where it transformed its curriculum and mode of educational delivery into a learner-driven teaching and learning model and added substantial elements of community-based education, exposure to rural service delivery, and research. Importantly, because of recognition that the urban-based medical schools effectively had been training for urban practice, the training of health care professionals is now organized in such a way that interdisciplinary cohorts of trainees spend at least 5 weeks every academic year living and working in a community.

With these changes in educational delivery and new emphasis on community-based learning we studied what the future plans of students at MakCHS (medicine, dentistry, nursing, and pharmacy) were with regard to: where they would seek to pursue postgraduate training (at home or abroad), where they intended to work (urban or rural practice), the proportion who planned to migrate from Uganda within the next 5,10 , or 15 years, and whether their origin from a rural or urban area influenced their decisions.

We report this data, discuss options to provide a sustainable supply of health care providers across the healthcare system of resource-constrained countries such as Uganda, and also call for changes in medical education and public policy that could be put in place to address international migration by graduates from health education programs.
TABLE 1: Number of respondents per health education discipline.

\begin{tabular}{lcc}
\hline Discipline & Number of students & Percentage \\
\hline Dentistry & 16 & 11.3 \\
Environmental health & 1 & 0.7 \\
Medicine & 74 & 52.5 \\
Nursing & 11 & 7.8 \\
Pharmacy & 38 & 27.0 \\
Undeclared & 1 & 0.7 \\
\hline Total & 141 & 100.0 \\
\hline
\end{tabular}

\section{Methods}

This was a descriptive cross-sectional study of students training at Makerere College of Health Sciences, Uganda (MakCHS). Our hypotheses were

(1) that the percentage of students in health care disciplines intending to emigrate in the next 5-15 years after graduation would be $>50 \%$ and

(2) that a rural or urban origin does not influence future practice location or plans to emigrate.

Questionnaires were developed iteratively, trialed for appropriate language and content, and distributed for anonymous completion between June to September 2008 to a random convenience sample of students at MakCHS recruited across all disciplines and from all years. Participation in the study was voluntary. Ethical approval for this collaborative study was obtained from the review boards of both MakCHS, Uganda, and the University of British Columbia, Canada.

A sample size of 150 was determined to be sufficient to be able to detect a difference between 50\% and 65\% in testing our primary hypothesis [17]. Data entry was done using an excel spread sheet and SPSS 12 for data analysis.

\section{Results}

Of the 141 respondents, 53\% were studying medicine, $27 \%$ pharmacy, $11 \%$ dentistry, $8 \%$ nursing, and $1 \%$ environmental health (Table 1). Sixty four percent had lived in urban areas before joining the MakCHS (45\% were from Kampala city). Eighty four percent of all respondents wished to do their postgraduate training outside Uganda, 14\% wanted to stay and pursue further studies at home, and $2 \%$ were undecided. The factors influencing their choice varied from an awareness of global educational opportunities, and perception that more comprehensive education and better clinical training were available abroad, to there being better long-term professional opportunities outside Uganda.

When asked where they planned to practice in the future the majority (57\%) expressed the desire to practice in urban areas and never saw themselves going to work in rural Uganda. As to whether they thought of emigrating from Uganda, 11 respondents $(8.5 \%)$ indicated that they never intended to emigrate, while $63 \%$ declared their intention to leave the country, with more than half intending to emigrate 
TABle 2: Principal reasons influencing the decision to emigrate.

\begin{tabular}{lcc}
\hline Reason & Number of students & Percentage \\
\hline Better pay & 72 & 51.1 \\
Better working conditions & 41 & 29.1 \\
Better opportunities \& career development & 23 & 16.3 \\
Poor/unstable political atmosphere/decisions perception of not being valued & 20 & 14.2 \\
Health not considered a national priority & 16 & 11.3 \\
Exposure to other working environments & 16 & 11.3
\end{tabular}

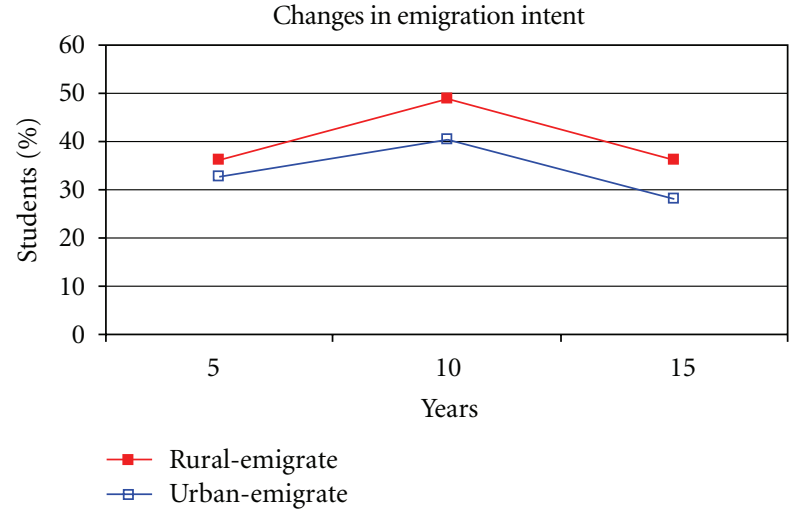

FIGURE 1: Immigration intent over time for students from rural and urban areas.

within 5-15 years of graduation. Amongst the reasons given for wanting to emigrate (Table 2) the principal response was because of better pay (51\%). Better working conditions were also considered important (29\%); better career opportunities and a more stable political environment were factors of significance for $14-16 \%$, and $11 \%$ of respondents cited national health policies and a feeling of not being valued as influencing their decision. Figure 1 shows a tendency for the majority of students to see themselves moving away over a 10 -year period, with some planning to possibly return after 15 years.

No significant differences were evident between the plans of students originating in rural versus urban areas in terms of the proportion planning to emigrate (Figure 1) or work in rural rather than urban practice.

\section{Discussion}

This study indicates that $63 \%$ of future health care professionals surveyed anticipated emigrating from Uganda, confirms our hypotheses, and indicates the extent of the burden international migration places on provision of health care services in Uganda. This is a problem Uganda shares with many other African countries; in Ghana $61 \%$ of doctors qualifying from a major medical school leave the country within ten years of graduating having given less than onethird of the expected duration of their professional services to their country [13]. The principal reason underlying the decision of our respondents to migrate was the expectation of better pay and working conditions. However, it is also clear that working conditions abroad are perceived to be better than at home in Uganda, and this is also an attraction.

It is an established strategy of developed countries to actively recruit personnel from international sources to solve their own HRH shortfalls $[2,18]$. Usually this occurs at the expense of the developing countries least able to afford the loss of such resources. Agreements to curb this "poaching" [15] have been called for and some attempts made [2, 13]. However, resolution of migration by this means is unlikely, as even if medical migration from resource-constrained countries was halted, although this would alleviate the shortage of human resources for health, it would not solve the problem entirely [19]. Similarly, while incentives (both financial and nonfinancial) would reduce the current distribution inequities in the global health workforce, such incentives, even if forthcoming, would be insufficient to achieve an equitable distribution alone.

Our finding that selection of students from rural versus urban areas has no bearing on the likelihood of them migrating, or influence on where they eventually plan to practice, is also relevant and in contrast to the belief that rural recruits are more likely to return to practice in rural areas. In Uganda pilot data from a program that provides comprehensive community-based learning opportunities during undergraduate education through participation in healthpromoting school programs suggests this learning experience is an effective means of introducing students to positive aspects of practice in a rural community. Moreover, this same program has been in place longer in Canada and has been shown to positively influence decisions by graduates from a pediatric residency program to work in rural and underserved communities [20]. Kaye et al. [11] and Schofiled at al. [12] have also identified that training location and environment are the predominant elements that influence career decisions related to practice location.

It is apparent that a range of "push" and "pull" factors contribute to international migration of skilled health professionals $[2,21]$. Educators and policy makers need to be aware that emigration is also predicated by poor health infrastructure, limited health policies, insufficient funding for health, and uncertainty regarding the political climate in a trainee's country of origin. The data from our study contribute to the importance of such recognition, but also emphasize that there are areas where committed countries can make improvements, which allows hope that retention of more graduates will result. Another telling but potentially 
remediable reason for migration we identified is the belief of trainees that they are not valued by either the health care system or by its leadership. Feelings such as this inevitably translate into limited motivation or desire to serve. To remedy this requires thought about how trainees are selected and educated and a major shift in the attitude and behavior of the teachers and leaders in the health care professions. As stated by Dovlo [13] "Governance and leadership in health must now be expressed as tangible actions that result in senior managers and policy makers valuing and respecting health workers". This is one issue compromising health care that is shared by both the developed and developing world. And while the "engaged and effective" leadership is central to achieving positive change, within education "leadership by example" and good mentorship are also creative elements that must be fostered and indeed championed in our globalization of medical education.

Consequently changes in how educational investment is made must be explored and functional policies formulated that will ensure the availability and equitable distribution of health care professionals where they are needed most. As recommended by the Global Health Workforce Alliance forum in Kampala [1] coherence across government sectors is required to achieve effective policies, particularly between health, education, trade, finance, labor, and local government agencies. This coordinated approach applied to migration has proved to be valuable in Thailand and Liberia and made personnel available in sufficient numbers to provide adequate and sustainable levels of service delivery across the healthcare system $[22,23]$.

In Uganda comparable capacity could be achieved if similar policies related to migration were enacted. The Ugandan constitution guarantees citizens that they can move freely wherever and whenever they want, but is silent on a citizen's social responsibility; while the right to education is included, an individual's responsibility to society after being educated in the public system is not. Taxpayers also contribute in some degree to the education of every individual health professional. Hence it is not unreasonable to make it a condition implicit in acceptance for health education that graduates work in the community for a defined period following internship. To make this practical and enforceable, all institutions of higher learning would be mandated not to release academic transcripts (these documents are required to work abroad) or award a full license until completion of this community-based practice. Then, on completion of this "bond" [24] and receipt of both transcripts and license individuals would be free to choose whether or not to undertake further training, where such training occurred, and where to work. The annual flow of graduates to the health centers that this policy would supply represents a sustainable critical mass that would make provision of a broad range of services more widely available. Based on their experience some of these individuals would also then be likely to choose to continue their role in the communities where they are working [20].

We recognize limitations in this study: particularly that the views of trainees were limited to students at the Makerere College of Health Sciences, and data from other institutions providing health care education was not obtained. However, to our knowledge this is one of the first studies of a cross-disciplinary cohort in that it provides data on future Ugandan physicians, dentists, nurses, and pharmacists, and our results are also comparable to those from a study on the future intentions of Ugandan nursing students [6]. Because both these studies identified that the decision to emigrate was driven by financial remuneration, the wish to work in a more politically stable country, and a desire to work in urban or private practice [6], we suggest our findings can likely be extrapolated to students in health care disciplines at other training institutions in Uganda, and probably to other African countries as well. We recognize that a period of compulsory postgraduate community service may appear restrictive, but such policy has both been suggested $[2,24]$ and adopted in various forms elsewhere $[22,23]$. Some medical schools in India include this requirement for mandatory community practice; Provinces in Canada require immigrant physicians to work in rural locations prior to full licensure, and in South Africa community service is required prior to full registration under Section $24 \mathrm{~A}$ of the Health Professions Act, 1974 [25].

\section{Conclusion}

The data from this study confirm that current healthcare professionals in training anticipate continuing the negative trend of migration from Uganda. The majority anticipate pursuing postgraduate training opportunities abroad and have no intention to practicing outside and urban setting. While international awareness of the problem of migration exists and some actions have been initiated, realistically a multifaceted approach is required including innovation and revitalization of health education, and novel and effective public policies. As in other countries the relevant ministries, educational institutions, and licensing bodies have to work together to develop strategies capable of generating the appropriate human resources required for health care delivery and placing them where they are needed. One option is a formal policy where all trainees entering education programs agree to a "bond" where as graduates they would be employed by government in community health centers for a period following graduation. Information from a survey such as the one we report and the concept of a "bond" may also be of use to other countries that unwillingly lose many of the health professionals they educate.
Abbreviations
MakCHS: College of Health Sciences, Makerere University
IMR: Infant mortality rate
HRH: Human resources for health
MMR: Maternal mortality rate
WHO: World health organization. 


\section{Conflict of Interests}

The authors declare that they have no conflict of interests.

\section{Acknowledgments}

Nevis Agirembabazi, Diane Kisakye, and Agnes Lematia of the College of Health Sciences, Makerere University, Kampala, Uganda, and Breanne Abbot, Gurpreet Dhaliwal, and Yunjin Sarah Park, of the University of British Columbia Medical School, Vancouver, Canada contributed to the questionnaire design and coordinated data collection. The authors are grateful for funding from the following: the University of British Columbia Teaching and Learning Enhancement Fund and Special Populations Fund; British Columbia's Children's Hospital Foundation; the Stellenbosch Institute for Advanced Study (STIAS), WallenbergResearchCentre at Stellenbosch University, South Africa, for post hoc support for A. Macnab, A. Kasangaki.

\section{References}

[1] WHO Global Health Workforce Alliance, The Kampala Declaration and Agenda for Global Action. Health Workers for All and All for Health Workers, World Health Organization, Geneva, Switzerland, 2008.

[2] O. B. Ahmad, "Managing medical migration from poor countries," British Medical Journal, vol. 331, no. 7507, pp. 4345, 2005.

[3] World Health Organization, "Report of the Secretariat on the determinants of health," WHO Document EB114/5, World Health Organization, Geneva, Switzerland, 2004.

[4] M. A. Clemens and G. Pettersson, "New data on African health professionals abroad," Human Resources for Health, vol. 6, article no. 1, 2008.

[5] F. Mullan, "The metrics of the physician brain drain," New England Journal of Medicine, vol. 353, no. 17, pp. 1810-1818, 2005.

[6] M. A. Goddard, C. J. Post, W. R. English, and J. W. Pike, "Examining the impacts of changing land use on biological integrity in streams using Geographical Information Systems and statistical modeling," Aquatic Ecosystem Health and Management, vol. 11, no. 2, pp. 230-242, 2008.

[7] A. K. Mbonye, M. G. Mutabazi, J. B. Asimwe et al., "Declining maternal mortality ratio in Uganda: priority interventions to achieve the millennium development goal," International Journal of Gynecology and Obstetrics, vol. 98, no. 3, pp. 285290, 2007.

[8] S. Ssewanyana and S. D. Younger, "Infant mortality in Uganda: determinants, trends and the millennium development goals," Journal of African Economies, vol. 17, no. 1, pp. 34-61, 2008.

[9] A. Hagopian, M. J. Thompson, M. Fordyce, K. E. Johnson, and L. G. Hart, "The migration of physicians from sub-saharan Africa to the United States of America: measures of the African brain drain," Human Resources for Health, vol. 2, 2004.

[10] Millennium Declaration 2000. http://www.un.org/millennium/declaration/ares552e.htm.

[11] D. K. Kaye, A. Mwanika, and N. Sewankambo, "Influence of the training experience of Makerere University medical and nursing graduates on willingness and competence to work in rural health facilities," Rural and Remote Health, vol. 10, no. 1, p. $1372,2010$.
[12] D. Schofield, S. Fletcher, J. Fuller, H. Birden, and S. Page, "Where do students in the health professions want to work?" Human Resources for Health, vol. 7, no. 1, p. 74, 2009.

[13] D. Dovlo, "Wastage in the health workforce: some perspectives from African countries," Human Resources for Health, vol. 3, 2005.

[14] F. El-Jardali, D. Jamal, A. Abdallah, and K. Kassak, "Human resources for health planning and management in the Eastern Mediterranean region: facts, gaps and forward thinking for research and policy," Human Resources for Health, vol. 5, article no. 9, 2007.

[15] The Lancet, "Poaching nurses from the developing world," The Lancet, vol. 367, no. 9525, p. 1791, 2006.

[16] J. B. Eastwood, R. E. Conroy, S. Naicker, P. A. West, R. C. Tutt, and J. Plange-Rhule, "Loss of health professionals from subSaharan Africa: the pivotal role of the UK," The Lancet, vol. 365, no. 9474, pp. 1893-1900, 2005.

[17] R. V. Lenth, "Java applets for power and sample size," [Computer software], 2006, http://www.stat.uiowa.edu/ rlenth/Power.

[18] A. J. Macnab, A. Kasangaki, and F. Gagnon, "Health promoting schools provide community-based learning opportunities conducive to careers in rural practice," International Journal of Family Medicine, vol. 2011, Article ID 892518, 5 pages, 2011.

[19] S. T. Varpilah, M. Safer, E. Frenkel, D. Baba, M. Massaquoi, and G. Barrow, "Rebuilding human resources for health: a case study from Liberia," Human Resources for Health, vol. 9, article 11, 2011.

[20] S. Wibulpolprasert and P. Pengpaibon, "Integrated strategies to tackle the inequitable distribution of doctors in Thailand: for decades of experience," Human Resources for Health, vol. 1, article no. 12, 2003.

[21] J. Buchan and G. Perfilieva, "Health worker migration in the European region: country case studies and policy implications," Tech. Rep. E88366, World Health Organization, Copenhagen, Denmark, 2006.

[22] B. Pond and B. McPake, "The health migration crisis: the role of four Organisation for Economic Cooperation and Development countries," The Lancet, vol. 367, no. 9520, pp. 1448-1455, 2006.

[23] J. P. Martin, The Medical Brain Drain: Myths and Realities (editorial), International Migration Outlook, OECD, 2007.

[24] R. Labonté, C. Packer, and N. Klassen, "Managing health professional migration from sub-Saharan Africa to Canada: a stakeholder inquiry into policy options," Human Resources for Health, vol. 4, article no. 22, 2006.

[25] Health Professions Council of South Africa, http//www.hpcsa. co.za/board_meddent_registration.php. 

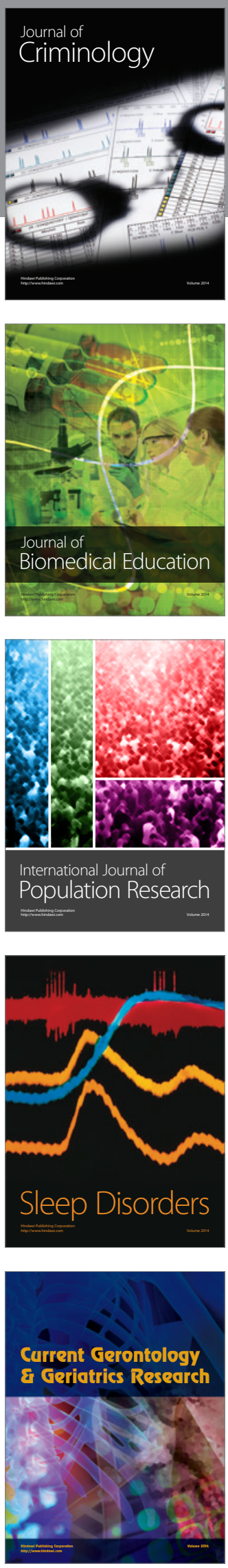
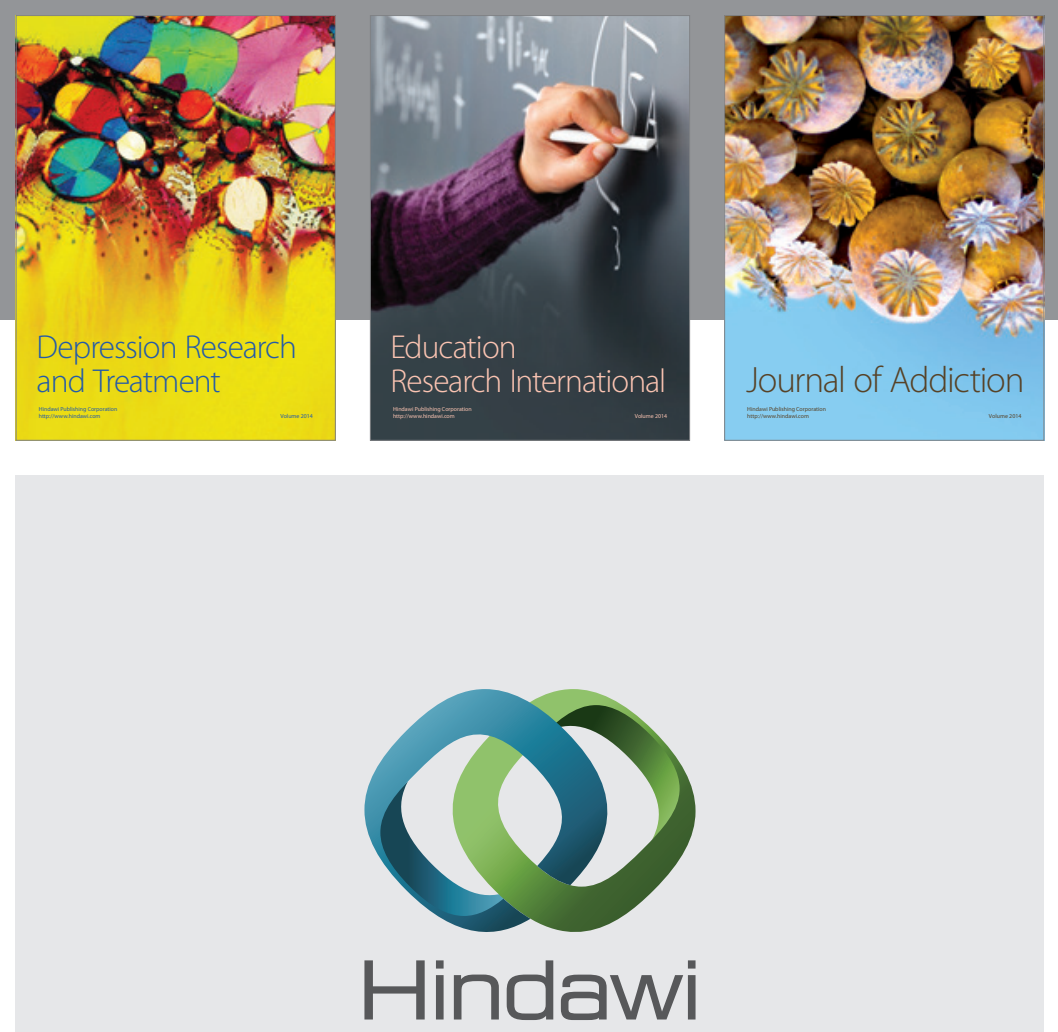

Submit your manuscripts at

http://www.hindawi.com

Child Development Research
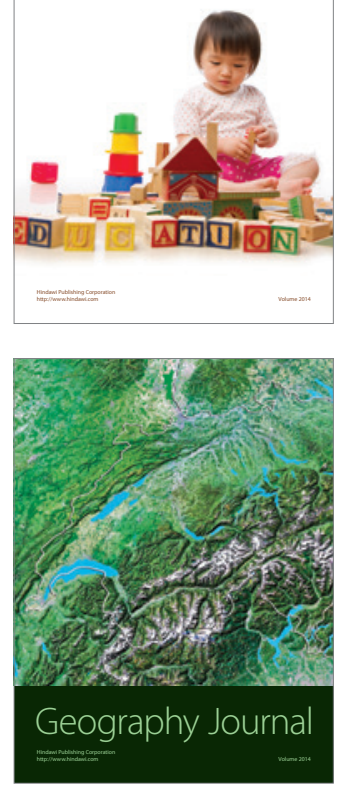

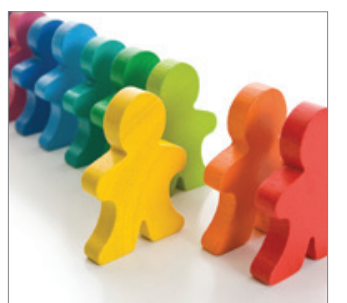

Autism

Research and Treatment
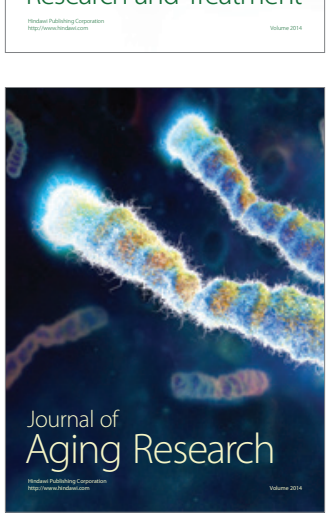
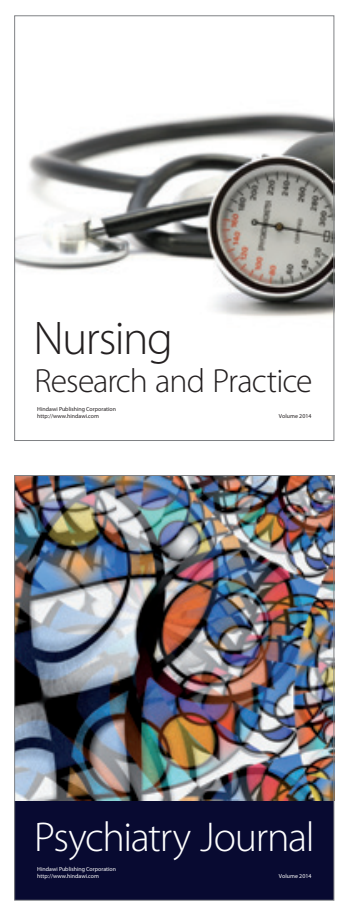
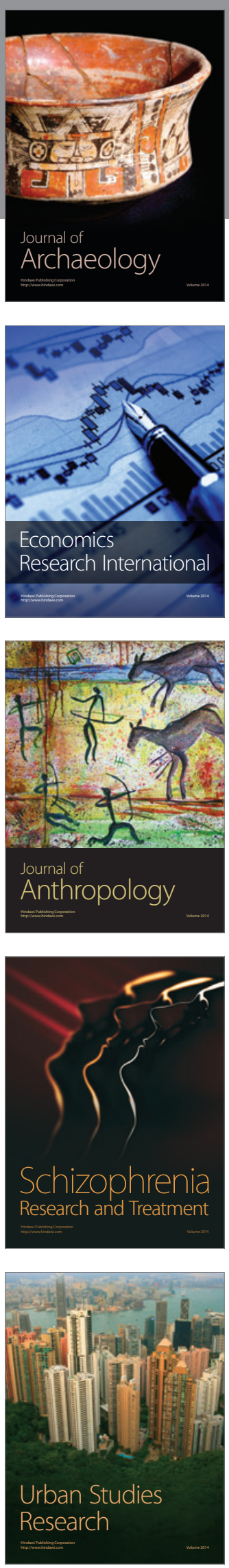